\title{
Associação Entre as Dimensões do Suporte Organizacional Percebido e a Intenção de
} Saída do Trabalho

\section{Association Between the Dimensions of Perceived Organizational Support and the Intention to Leave Work}

\author{
Raniely Araújo Silva Moraes ${ }^{1}$, Sérgio Augusto Pereira Bastos ${ }^{* 2}$ \\ ${ }^{1}$ Instituto Federal do Maranhão (IFMA), Maranhão, Brasil. \\ ${ }^{2}$ FUCAPE Business School, Maranhão, Brasil.
}

\begin{tabular}{|c|c|}
\hline I NFO A R I GO & RESUMO \\
\hline $\begin{array}{l}\text { Palavras-chave: } \\
\text { Suporte Organizacional } \\
\text { Percebido, } \\
\text { Intenção de Saída do } \\
\text { Trabalho, } \\
\text { Consequências Negativas na } \\
\text { Carreira, } \\
\text { Gestão de Recursos } \\
\text { Humanos. }\end{array}$ & $\begin{array}{l}\text { Entender as forças que levam um trabalhador a desejar sair do trabalho é um desafio, } \\
\text { dada a crescente importância do gerenciamento do capital intelectual e a potencial } \\
\text { perda para a organização com a rotatividade (turnover). Assim, o objetivo deste estudo } \\
\text { foi identificar as dimensões do suporte organizacional percebido que afetam a intenção } \\
\text { de saída do trabalho, sob o ponto vista dos empregados. Foi realizada uma pesquisa } \\
\text { quantitativa com amostra não probabilística por acessibilidade de profissionais de } \\
\text { organizações púbicas e privadas situadas na Região Nordeste do Brasil. Foram } \\
\text { investigados cinco construtos para caracterizar o suporte organizacional percebido } \\
\text { pelo trabalhador. Os resultados indicaram que a intenção de saída do trabalho pode ser } \\
\text { afetada positivamente pelas dimensões "apoio organizacional" e "política de apoio a } \\
\text { dependentes", e negativamente pela dimensão "consequências negativas na carreira". } \\
\text { Há, no entanto, outros fatores não investigados que podem ampliar o poder de explicar } \\
\text { a intenção de saída do trabalho. Como contribuição teórica, há que destacar a } \\
\text { relevância da discussão do suporte organizacional percebido para a intenção de saída } \\
\text { do trabalho em um ambiente destrói empregos em função de novas tecnologias e } \\
\text { modelos de negócios. }\end{array}$ \\
\hline ARTICLE INFO & A B S T R ACT \\
\hline $\begin{array}{l}\text { Keywords: } \\
\text { Perceived Organizational } \\
\text { Support, } \\
\text { Leave Work Intention, } \\
\text { Negative Consequences in } \\
\text { Career, } \\
\text { Human Resources } \\
\text { Management. }\end{array}$ & $\begin{array}{l}\text { Understanding the forces that lead a worker to want to leave work is a challenge, given } \\
\text { the growing importance of intellectual capital management and the potential loss to } \\
\text { the organization with turnover. Thus, the objective of this study was to identify the } \\
\text { dimensions of the perceived organizational support that affect the intention to leave } \\
\text { the work, from the point of view of the employees. A quantitative survey was } \\
\text { performed with a non-probabilistic sample non-probabilistic sample for accessibility } \\
\text { from professionals of public and private organizations located in the Northeast Region } \\
\text { of Brazil. Five constructs were investigated to characterize the organizational support } \\
\text { perceived by the worker. The results indicated that the intention to leave can be } \\
\text { positively affected by the dimensions "organizational support" and "support policy for } \\
\text { dependents", and negatively by the dimension "negative consequences in the career". } \\
\text { There are, however, other uninvestigated factors that may increase the power to } \\
\text { explain the intention to leave the work. As theoretical contribution, it is important to } \\
\text { highlight the discussion of perceived organizational support for the intention to leave } \\
\text { work in an environment which destroys jobs due to new technologies and business } \\
\text { models. }\end{array}$ \\
\hline
\end{tabular}

\footnotetext{
* Principal contato para correspondência.

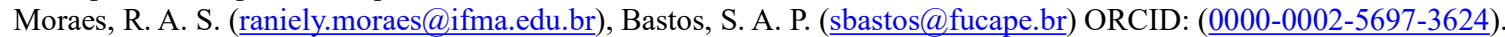

DOI: dx.doi.org/10.21714/1679-18272019v17Ed.p105-1119

1679-1827 C 2019 Gest@o.org. 


\section{Introdução}

Garantir o melhor rendimento dos Recursos Humanos (RH) para dispor de vantagens competitivas e reconhecimento no mercado em que atuam, é um dos principais desafios das organizações. Este fato gera nas organizações a necessidade de implementar ações que proporcionem o aumento da fidelidade na relação empregado-empregador (PURANG, 2011).

A gestão executiva das organizações está preocupada em mantê-las competitivas, por meio do desenvolvimento de estratégias que possibilitem atrair, contratar, desenvolver e reter talentos, visando minimizar a falta de engajamento entre organização e trabalhador, o que traz sérias consequências para o desempenho da organização (FRANK; FINNEGAN; TAYLOR, 2004).

$\mathrm{Na}$ relação entre organização e trabalhador, as organizações estão interessadas em envolver e manter os profissionais energizados e produtivos no trabalho e comprometidos com a organização. Enquanto isso, os profissionais estão interessados no que a organização vai fazer por eles em termos de recompensas organizacionais e condições de trabalho favoráveis (JAMES et al., 2011).

Nesse sentido, o suporte organizacional percebido, embora seja um construto já estabelecido na literatura, continua relevante e com possibilidades de novas abordagens empíricas e contribuições teóricas. $\mathrm{O}$ fato de o suporte organizacional percebido influenciar o aumento da satisfação e comprometimento no trabalho, o sentimento de pertencer à organização e o propósito em permanecer na organização tem reforçado a relevância do tema (RHOADES; EISENBERGER, 2002; ESTIVALETE; ANDRADE, 2012). É caracterizado por convicções desenvolvidas pelos profissionais sobre a amplitude em que a organização valoriza os seus esforços e preocupa-se com seu bem-estar, com o intuito de promover vantagens mútuas na relação entre esses agentes (ESTIVALETE; ANDRADE, 2012).

As características do trabalho estão associadas à satisfação no trabalho, comprometimento organizacional e intenção de rotatividade. Dessa forma, as práticas de RH podem ser utilizadas como ferramentas organizacionais para reforçar o sentimento dos funcionários de que a organização valoriza o seu trabalho e se preocupa com o seu bem-estar, colaborando para reduzir a intenção de rotatividade (CHANG; WANG; HUANG, 2013).

Noronha (2015), que investigou a relação entre o suporte organizacional percebido e a intenção de saída da organização, propôs que esta relação fosse investigada em outras regiões do Brasil, tendo em vista que a totalidade da sua amostra tinha origem em uma única cidade (Vitória - ES). Também sugeriu que novas investigações fossem realizadas em diferentes culturas organizacionais e segmentos de negócios, já que seu estudo se limitou a avaliar a percepção de empregados de organizações da área industrial e de serviços.

O objetivo deste estudo é, portanto, identificar as dimensões do suporte organizacional, percebidas pelo trabalhador, que afetam a sua intenção de saída do emprego, tendo como foco a região Nordeste do Brasil, de cultura e condições socioeconômicas particulares.

O entendimento acerca das inter-relações entre as dimensões do suporte organizacional percebido e a intenção de sair da organização passa pela investigação das práticas de RH formais e informais que, na visão dos empregados, estão associadas ao comprometimento organizacional e a retenção de funcionários, tema abordado dentre outros por Chew e Chan (2008).

Cabe um destaque quanto ao uso das palavras trabalhador, empregado, funcionário e colaborador. Para fins deste estudo, são consideradas sinônimos, sendo utilizadas indistintamente, apenas respeitando o seu uso pelos diversos autores citados.

\section{Fundamentação Teórica}

\subsection{Suporte Organizarional Percebido}

Na relação entre trabalhador e organização ocorre uma troca, com o intuito da promoção de vantagens mútuas, em que a expectativa de reconhecimento e retribuição concedida pela organização como compensação ao trabalho realizado estão diretamente relacionadas ao suporte organizacional percebido. Neste cenário, verifica-se a existência de perspectivas de reciprocidade no convívio entre indivíduo e organização (ESTIVALETE; ANDRADE, 2012). Para identificar o suporte organizacional percebido, o presente estudo utiliza-se de cinco dimensões ou construtos a partir da literatura, a seguir detalhada: "apoio organizacional", "flexibilidade de horário", "política de apoio a dependentes", "suporte gerencial" e "consequências negativas na carreira".

O senso de dever e comprometimento afetivo proporcionados pelo suporte organizacional percebido podem estimular nos colaboradores a necessidade de cuidar da organização e colaborar para atingir seus objetivos (RHOADES; EISENBERGER, 2002). Nesta linha, o "apoio organizacional" é concedido sob a forma de 
incentivos materiais e socioemocionais aos seus profissionais, visando receber em troca seu empenho e esforço no trabalho. Logo o suporte organizacional é percebido pelos trabalhadores por meio do tratamento positivo da organização em termos de equidade, condições de trabalho e de supervisão nas relações (ZAGENCZYK et al., 2011).

A autonomia no trabalho possibilita a liberdade, discrição e independência para escolha do horário de trabalho, tomada de decisões e procedimentos e métodos para execução das atividades. Tal "flexibilidade de horário" está associada com a elevação de níveis de compromisso entre empregado e empregador, especialmente com o comprometimento afetivo do empregado em manter sua permanência na organização e disponibilizar seu trabalho para alcance dos objetivos organizacionais (GALLETTA; PORTOGHESE; BATTISTELLI, 2011). A administração de ações que proporcionam o equilíbrio entre vida pessoal e vida profissional, geralmente, referemse ao suporte que a organização oferece para cuidados com dependentes, às alternativas de flexibilidade no trabalho, e à licença para cuidar de questões particulares ou familiares (BEAUREGARD; HENRY, 2009).

A Teoria da Troca Social sugere que, quando os funcionários percebem a contribuição da organização com a prestação de cuidados e apoio aos seus dependentes, ocorre uma retribuição através de atitudes e comportamentos positivos. Com essa "política de apoio a dependentes", parte do suporte organizacional percebido, está associada ao aumento da satisfação no trabalho e do compromisso organizacional e à redução do turnover (WAYNE et al., 2013).

Nas organizações, o superior imediato é a primeira pessoa a quem os funcionários se reportam, o que os leva a reconhecerem naqueles um maior compromisso com a organização. Dessa forma, quando os funcionários percebem o "suporte organizacional" por meio da atenção de seus supervisores imediatos, há um reforço do sentimento de permanecer na organização (NASHUKI; OTHMAN; GHAZALI, 2014).

Políticas organizacionais que proporcionam apoio à família do empregado estão associadas com a redução de "consequências negativas na carreira", como o conflito trabalho-família, a intenção de sair da organização e o burnout ("queimar o empregado"), assim como consequências positivas, como a elevação dos níveis de satisfação no trabalho e comprometimento afetivo com a organização (WAYNE et al., 2013).

O nível de envolvimento entre os funcionários e a organização é uma resposta às políticas e práticas de suporte organizacionais, que podem implicar comportamentos negativos ou positivos desenvolvidos pelos trabalhadores no ambiente de trabalho. Assim, o desejo de permanecer na organização varia de acordo com o nível de engajamento nas relações organizacionais (ABUKHALIFEH; SOM, 2013).

\subsection{Intenção de Saída do Trabalho}

A rotatividade ou turnover trata-se de uma interrupção na relação de emprego entre o indivíduo e a organização, que pode proporcionar impactos negativos na performance e na perda de conhecimento tácito pela organização, já que os funcionários desenvolvem competências e habilidades durante a sua associação com a organização. Além disso, podem gerar custos adicionais e se relacionar negativamente com a imagem da empresa, que pode a ser vista como má empregadora (SHAHNAWAZ; JAFRI, 2009).

$\mathrm{O}$ ajuste da relação entre empregado e organização está relacionado com atitudes de trabalho, que podem gerar sentimentos de retribuição, com a manifestação de maior comprometimento e redução dos estímulos para deixar a organização, em contrapartida proporcionando à organização o atendimento dos seus requisitos (CHEW; CHAN, 2008). Além disso, as práticas de recursos humanos, que influenciem o suporte organizacional percebido, possibilitam um maior envolvimento na relação entre empregado e empregador e favorecem o estabelecimento de um clima de trabalho positivo, contribuindo para a redução na intenção de sair da organização (CHANG; WANG; HUANG, 2013).

Neste sentido, é necessário que as organizações tenham conhecimento sobre os fatores que influenciam a redução da intenção de saída dos empregados da organização, de forma a mitigá-la e permitir a concentração nos fatores que fomentam o desejo dos funcionários em permanecer na organização (CHO; JOHANSON; GUCHAIT, 2009).

\subsection{Articulação Teórica e Hipóteses de Pesquisa}

Conforme exposto, considerou-se o suporte organizacional representado pelos construtos "suporte gerencial", "apoio organizacional", "flexibilidade de horário", "politica de apoio a dependentes" e "consequências negativas na carreira". Argumenta-se que o suporte organizacional influencia a intenção de saída do empregado, ou seja, impacta a rotatividade (turnover) nas empresas. Isso condiz com os achados de Luz, Paula e Oliveira (2018), que 
apontaram a redução do turnover em função de comprometimentos afetivos e normativos e da satisfação no trabalho. Adicionalmente, levam-se duas possibilidades de diferenças de percepções entre homens e mulheres e entre empregados do setor público e do setor privado. Com isso são seguintes as hipóteses de pesquisa:

- H1: o suporte gerencial é negativamente proporcional à intenção de saída do trabalho.

- H2: o apoio organizacional é negativamente proporcional à intenção de saída do trabalho.

- H3: a flexibilidade de horário é negativamente proporcional à intenção de saída do trabalho.

- H4: a política de apoio a dependentes é negativamente proporcional à intenção de saída do trabalho.

- H5: as consequências negativas na carreira são positivamente proporcionais à intenção de saída do trabalho.

- H6: há diferenças de percepções quanto ao suporte organizacional e a intenção de saída entre homens e mulheres.

- H7: há diferenças de percepções quanto ao suporte organizacional e a intenção de saída entre empregados dos setores público e privado.

\section{Metodologia}

Para alcançar o objetivo proposto foi realizada uma pesquisa de natureza quantitativa com corte transversal e natureza descritiva. A unidade de análise foi composta por profissionais que mantém vínculo empregatício em organizações da esfera pública e privada, em dois Estados da Região Nordeste do Brasil (Maranhão e Piauí), abrangendo servidores públicos e profissionais do setor privado, com atuação nos segmentos de comércio, educação, saúde e indústria. Esses segmentos conferem riqueza aos resultados da pesquisa pela diversidade de experiências dos trabalhadores. A amostra foi não probabilística e por acessibilidade, foi composta por profissionais que tivessem opinião formada sobre os temas pesquisados. Assim, de acordo com Noronha (2015), torna-se mais viável avaliar quais as dimensões do suporte organizacional percebido, na visão dos empregados, estão associadas à retenção dos mesmos.

Para a coleta de dados foi utilizado questionário composto por 41 itens, adaptado a partir de questionários validados por De Oliveira, Cavazotte e Paciello (2013); Anderson, Coffey e Byerly (2002); Noronha (2015); e Nashuki, Othman e Ghazali (2014). Em sua composição constam 7 itens relacionadas à caracterização do entrevistado (idade, gênero, estado civil, formação acadêmica, local de trabalho, grau hierárquico e tempo de serviço na empresa), a questão de controle relativa ao vínculo empregatício, 29 itens relacionados com as dimensões do suporte organizacional percebido, distribuídos pelos citados 5 construtos, e 5 itens relacionados ao construto de intenção de saída. Quanto aos construtos, foram feitas afirmações cujas percepções por parte dos respondentes foram captadas por escala Likert de concordância de 5 pontos, variando de 1, discordo totalmente, a 5 , concordo totalmente.

O instrumento de coleta de dados foi submetido a um pré-teste aplicado a 10 respondentes. Não houve qualquer necessidade de ajuste. Em seguida, foi distribuído ao público-alvo em esquema "bola de neve", por meio de ferramentas on-line, utilizando o Google Docs, e, também, aplicado pessoalmente.

Foram obtidas 385 respostas, das quais 365 válidas. Os questionários desconsiderados estavam incompletos ou houve resposta negativa à questão de controle: "você exerce atualmente atividade remunerada em empresa privada, empresa pública / economia mista, ONG / terceiro setor, ou trabalha para o Governo?". A quantidade de respostas válidas atende aos requisitos de validade da amostra, conforme Hair Jr., Black, Babin e Tatham (2009).

Os dados foram analisados por meio de estatística descritiva, regressão linear múltipla e teste de médias, nesse caso para avaliar possíveis diferenças de percepções entre gêneros e local de trabalho (administração pública e iniciativa privada). A equação (1) indica o modelo de pesquisa.

$$
\mathrm{IS}=\alpha+\beta 1 * \mathrm{SG}+\beta 2 * \mathrm{AO}+\beta 3 * \mathrm{FH}+\beta 4 * \mathrm{PAD}+\beta 5^{*} \mathrm{CNC}+\varepsilon
$$

Onde:

- IS: variável dependente, indicando a intenção de saída do trabalho;

- SG: variável independente, indicando o suporte gerencial;

- AO: variável independente, indicando o apoio organizacional;

- FH: variável independente, indicando a flexibilidade horários;

- PAD: variável independente, indicando a política de apoio a dependentes; e

- CNC: variável independente, indicando as consequências negativas na carreira. 


\section{Análise dos Dados}

\subsection{Perfil da População Economicamente Ativa na Região Nordeste do Brasil}

Esta análise inicial tem como objetivo informar características gerais sobre a unidade de análise investigada neste estudo; trabalhadores que atuam em organizações da esfera pública e privada, particularmente na Região Nordeste do Brasil, e com isto facilitar a verificação da adequação entre a amostra de respondentes do questionário e o perfil da população analisada. Segundo a Pesquisa Nacional por Amostra de Domicílios Contínua - PNAD Contínua, realizada pelo Instituto Brasileiro de Geografia e Estatística - IBGE (IBGE, 2016), a população ocupada da região Nordeste apresentou, no $2^{\circ}$ trimestre de 2016, as seguintes características:

$\rightarrow$ Taxa de participação de $48,6 \%$ da população em idade de trabalhar presente na força de trabalho, sendo $86,8 \%$ ocupada e 13,2\% desocupada. Dos ocupados, há predominância de homens $(58,6 \%)$.

$\rightarrow$ O contingente de ocupados, indicou que 13\% deles são jovens, entre 18 e 24 anos; que os adultos, aqueles na faixa de 2559 anos de idade, representavam 78,5\%; e que os idosos correspondiam a 6,4\%.

$\rightarrow$ Entre as pessoas ocupadas, 26,5\% não tinham concluído o ensino fundamental, 30\% tinham concluído pelo menos o ensino médio e $12,5 \%$ tinham concluído o nível superior.

$\rightarrow$ A população ocupada é composta por 62,5\% de empregados, 2,9\% de empregadores, 31,3\% de pessoas que trabalharam por conta própria e 3,3\% de trabalhadores familiares auxiliares.

$\rightarrow$ Parte expressiva, 66,4\%, empregados estava alocada no setor privado, 22,5\% no setor público e $11,1 \%$ no serviço doméstico.

$\rightarrow$ O percentual de empregados com carteira de trabalho assinada no setor privado era de $62,2 \%$.

\subsection{Caracterização da Amostra}

A Tabela 1 contém a caracterização da amostra. Em relação ao local de trabalho, 32,1\% dos respondentes trabalham na iniciativa privada em comércio, $31,2 \%$ na iniciativa privada em serviços e 26,8\% atua na administração pública. Apesar da amostra apresentar profissionais com diferentes níveis hierárquicos, a grande maioria dos respondentes atua no nível operacional abrangendo $61,1 \%$ dos respondentes, seguindo-se os especialistas/analistas $(19,5 \%$ da amostra). Por fim, com relação ao tempo de serviço, identificou-se que 46,8 \% dos profissionais estão há mais de 4 anos em suas organizações, seguidos daqueles com mais de 3 até 4 anos $(12,9 \%)$ e mais de 1 até 2 anos $(12,6 \%)$. Verifica-se que a amostra condiz com perfil da população pesquisada conforme apresentado no item 4.1 , estando adequada ao objetivo desta investigação.

Tabela 1. Caracterização da Amostra.

\begin{tabular}{|c|c|c|c|}
\hline Característica & Variáveis & Frequência & $\%$ \\
\hline \multirow{5}{*}{ Idade } & Até 25 anos & 56 & 15,3 \\
\hline & Entre 26 e 35 anos & 197 & 54,0 \\
\hline & Entre 36 e 45 anos & 86 & 23,6 \\
\hline & Entre 46 e 55 anos & 25 & 6,8 \\
\hline & Mais de 55 anos & 1 & ,3 \\
\hline \multirow{2}{*}{ Gênero } & Feminino & 218 & 59,7 \\
\hline & Maculino & 147 & 40,3 \\
\hline \multirow{4}{*}{ Estado Civil } & Solteiro(a) & 160 & 43,8 \\
\hline & Casado(a) & 169 & 46,3 \\
\hline & Divorciado(a) & 10 & 2,7 \\
\hline & Outro & 26 & 7,1 \\
\hline \multirow{6}{*}{ Escolaridade } & Ensino Fundamental & 6 & 1,6 \\
\hline & Ensino Médio & 105 & 28,8 \\
\hline & Tecnólogo/Técnico & 32 & 8,8 \\
\hline & Graduado & 92 & 25,2 \\
\hline & Pós-graduação (Lato Sensu) & 91 & 24,9 \\
\hline & Mestrado/Doutorado (Stricto Sensu) & 35 & 9,6 \\
\hline
\end{tabular}




\begin{tabular}{|c|c|c|c|}
\hline & Outro & 4 & 1,1 \\
\hline \multirow{5}{*}{ Local de Trabalho } & Adminitração Pública & 98 & 26,8 \\
\hline & Iniciativa Privada (indústria) & 6 & 1,6 \\
\hline & Iniciativa Privada (comércio) & 114 & 31,2 \\
\hline & Iniciativa Privada (serviço) & 117 & 32,1 \\
\hline & Outros & 30 & 8,2 \\
\hline \multirow{5}{*}{ Grau Hierárquico } & Operacional & 223 & 61,1 \\
\hline & Especialista/Analista & 71 & 19,5 \\
\hline & Supervisão & 31 & 8,5 \\
\hline & Gerência & 29 & 7,9 \\
\hline & Diretoria & 11 & 3,0 \\
\hline \multirow{6}{*}{$\begin{array}{c}\text { Tempo de Serviço da } \\
\text { Empresa }\end{array}$} & Menos de 6 meses & 31 & 8,5 \\
\hline & Mais de 6 meses a 1 ano & 32 & 8,8 \\
\hline & Mais de 1 ano a 2 anos & 46 & 12,6 \\
\hline & Mais de 2 anos a 3 anos & 38 & 10,4 \\
\hline & Mais de 3 anos a 4 anos & 47 & 12,9 \\
\hline & Mais de 4 anos & 171 & 46,8 \\
\hline Total & & 365 & 100 \\
\hline
\end{tabular}

Fonte: Elaborado pelos autores a partir de dados da pesquisa.

\subsection{Estatística Descritiva}

Foram observados as médias e os desvios padrão das 34 variáveis que compõem os 6 construtos, o que se encontram na Tabela 2.

Verifica-se que, de forma geral, os respondentes tendem a considerar as variáveis que compõem o construto "suporte gerencial" $(M=3,130 ; D P=1,065)$, um pouco acima da neutralidade. Destaque para as percepções com tendência à concordância sobre os gestores imediatos com as variáveis "Meu chefe me dá suporte quando eu tenho alguma demanda familiar ou pessoal em que eu necessite ausentar-me do trabalho (por exemplo, consulta médica, reunião na escola dos filhos etc.)" $(M=3,710 ; D P=1,259)$ e a "Meu chefe me dá suporte quando eu tenho um problema de trabalho" $(M=3,430 ; D P=1,268)$. Porém, quando se referem a "Meu chefe realmente se importa com os efeitos que as demandas do trabalho exercem sobre minha vida pessoal e familiar" $(M=2,710 ; D P=$ $1,257)$ e "Sinto-me confortável em trazer meus problemas pessoais ou familiares ao conhecimento do meu chefe" $(M=2,466 ; D P=1,378)$ os respondentes tendem a considerar que os gestores não concordam.

Tabela 2. Estatísitica Descritiva.

\begin{tabular}{|c|c|c|c|}
\hline Construto & Variáveis & Média & $\begin{array}{l}\text { Desvio } \\
\text { Padrão }\end{array}$ \\
\hline \multirow{5}{*}{$\begin{array}{l}\text { Suporte Gerencial } \\
\text { (SG) }\end{array}$} & Total SG & 3,130 & 1,065 \\
\hline & $\begin{array}{l}\text { Meu chefe me dá suporte quando eu tenho alguma demanda familiar } \\
\text { ou pessoal em que eu necessite ausentar-me do trabalho (por exemplo, } \\
\text { consulta médica, reunião na escola dos filhos etc.). }\end{array}$ & 3,710 & 1,259 \\
\hline & Meu chefe me dá suporte quando eu tenho um problema de trabalho. & 3,430 & 1,268 \\
\hline & $\begin{array}{l}\text { Meu chefe é compreensivo quando falo de questões e problemas } \\
\text { pessoais ou familiares que afetam meu trabalho. }\end{array}$ & 3,285 & 1,333 \\
\hline & $\begin{array}{l}\text { Meu chefe é justo e imparcial, ou seja, não desfavorece funcionários } \\
\text { em função das necessidades pessoais e familiares dos mesmos. }\end{array}$ & 3,277 & 1,296 \\
\hline
\end{tabular}




\begin{tabular}{|c|c|c|c|}
\hline & $\begin{array}{l}\text { O suporte do meu chefe é determinante para que eu não tenha intenção } \\
\text { de sair da organização em que trabalho. }\end{array}$ & 3,036 & 1,284 \\
\hline & $\begin{array}{l}\text { Meu chefe realmente se importa com os efeitos que as demandas do } \\
\text { trabalho exercem sobre minha vida pessoal e familiar. }\end{array}$ & 2,710 & 1,257 \\
\hline & $\begin{array}{l}\text { Sinto-me confortável em trazer meus problemas pessoais ou familiares } \\
\text { ao conhecimento do meu chefe. }\end{array}$ & 2,466 & 1,378 \\
\hline & Total AO & 3,071 & $\mathbf{0 , 9 1 0}$ \\
\hline & $\begin{array}{l}\text { Eu percebo que, se houver oportunidade, a organização aproveitaria } \\
\text { ainda mais minhas habilidades e competências. }\end{array}$ & 3,403 & 1,172 \\
\hline & $\begin{array}{l}\text { Eu percebo que minha organização está disposta a me ajudar se eu tiver } \\
\text { uma necessidade especial. }\end{array}$ & 3,247 & 1,174 \\
\hline & $\begin{array}{l}\text { Eu percebo que minha organização realmente se importa com meu } \\
\text { bem-estar. }\end{array}$ & 3,211 & 1,173 \\
\hline & Eu percebo que minha organização se preocupa comigo e me valoriza. & 3,030 & 1,205 \\
\hline $\begin{array}{l}\text { Apoio Organizacional } \\
\qquad(\mathrm{AO})\end{array}$ & $\begin{array}{l}\text { As práticas adotadas pela organização em que trabalho para reter seus } \\
\text { profissionais são determinantes para que eu NÃO tenha intenção de } \\
\text { sair da organização. }\end{array}$ & 3,019 & 1,237 \\
\hline & $\begin{array}{l}\text { Eu percebo que os meios para me ajudar estão disponíveis na minha } \\
\text { organização quando tenho uma necessidade especial. }\end{array}$ & 3,000 & 1,102 \\
\hline & $\begin{array}{l}\text { Eu percebo que minha organização valoriza fortemente meus objetivos } \\
\text { e valores pessoais. }\end{array}$ & 2,970 & 1,205 \\
\hline & $\begin{array}{l}\text { Eu percebo que minha organização aceitaria um erro honesto de minha } \\
\text { parte. }\end{array}$ & 2,967 & 1,131 \\
\hline & Eu percebo que minha organização se preocupa com minhas opiniões. & 2,792 & 1,112 \\
\hline & Total FH & 2,527 & $\mathbf{0 , 9 0 8}$ \\
\hline & $\begin{array}{l}\text { A jornada de trabalho na minha empresa é fixa e eu não tenho } \\
\text { flexibilidade de escolha. }\end{array}$ & 3,200 & 1,428 \\
\hline $\begin{array}{l}\text { Flexibilidade de } \\
\text { Horário }\end{array}$ & $\begin{array}{l}\text { A flexibilidade de horário na organização em que trabalho é } \\
\text { determinante para que eu NÃO tenha intenção de sair da organização. }\end{array}$ & 2,592 & 1,269 \\
\hline (FH) & $\begin{array}{l}\text { A empresa em que trabalho permite que eu escolha um horário de } \\
\text { entrada e saída predefinido (por exemplo, de } 8: 00 \mathrm{hs} \text { às } 17: 00 \mathrm{hs} \text {, de } \\
9: 00 \text { às } 18: 00 \mathrm{hs} \text {, de } 10: 00 \mathrm{hs} \text { às } 19: 00 \mathrm{hs} \text { ). }\end{array}$ & 2,364 & 1,395 \\
\hline & Posso escolher livremente meu horário de entrada e saída. & 1,953 & 1,170 \\
\hline & Total PAD & 2,376 & 1,090 \\
\hline $\begin{array}{l}\text { Política de Apoio a } \\
\text { Dependentes }\end{array}$ & $\begin{array}{l}\text { Na empresa em que trabalho estou satisfeito com as políticas de apoio } \\
\text { disponibilizadas a dependentes (filhos, enteados, idosos etc.) como, } \\
\text { por exemplo, auxílio creche, licença remunerada, casa de repouso para } \\
\text { idosos, plano de saúde etc. }\end{array}$ & 2,627 & 1,344 \\
\hline & $\begin{array}{l}\text { As políticas de apoio a dependentes (filho, enteado, idosos etc.) são } \\
\text { determinantes para que eu NÃO tenha intenção de sair da organização. }\end{array}$ & 2,329 & 1,282 \\
\hline & Utilizo com frequência as políticas de apoio a dependentes (filhos, & 2,173 & 1,214 \\
\hline
\end{tabular}




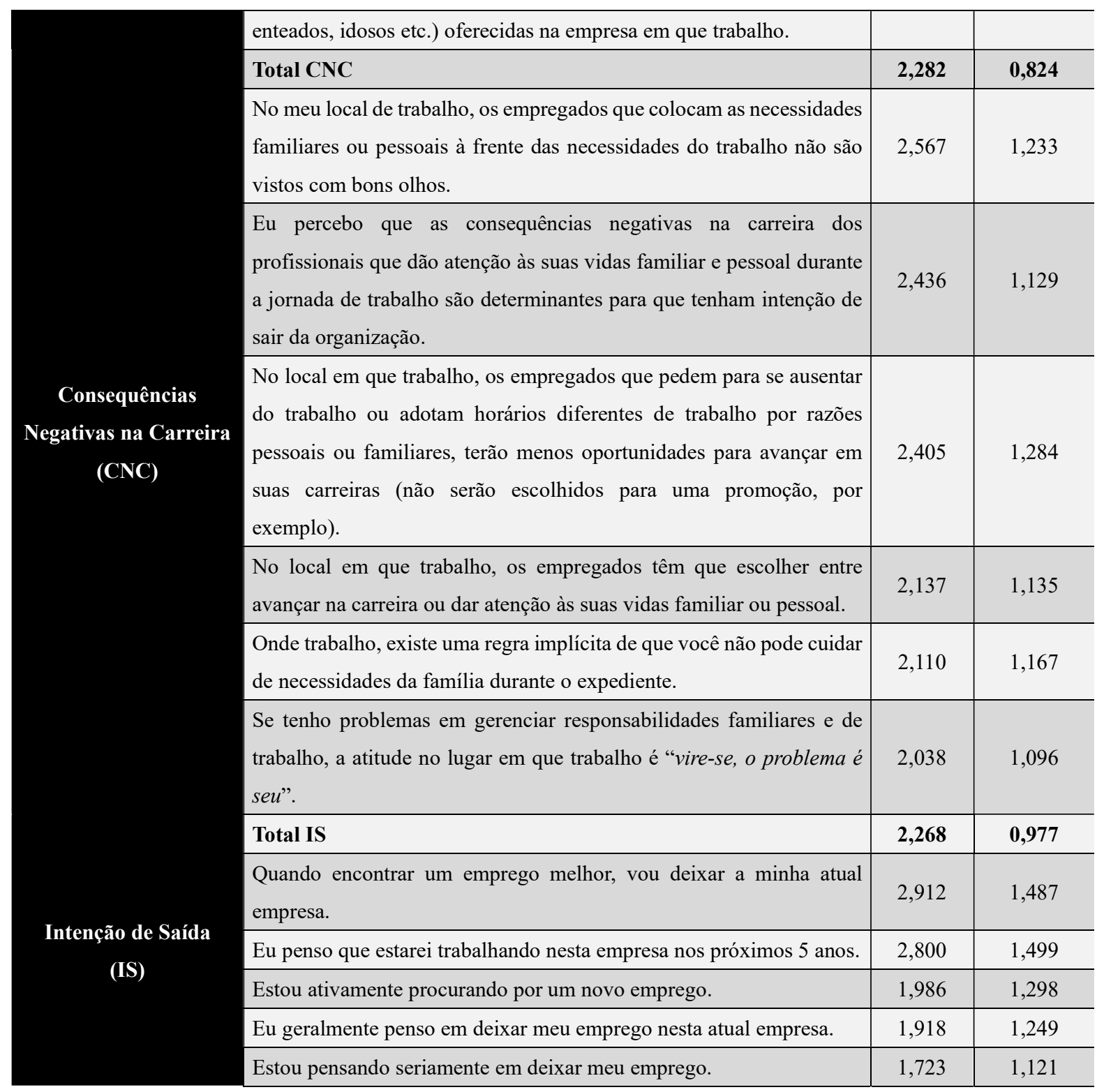

Fonte: Elaborado pelos autores a partir de dados da pesquisa.

Estes resultados ratificam o estudo de Nashuki, Othman e Ghazali (2014) em que, quando os funcionários percebem o suporte e a atenção de seus supervisores imediatos, há um reforço do sentimento de permanecer na organização, o que evidencia a relação positiva entre o suporte do supervisor e a intenção de ficar do seu subordinado. Com relação ao construto "apoio organizacional" $(M=3,071 ; D P=0,910)$, verificou-se uma média que sugere neutralidade. Além disso, o desvio padrão indica variabilidade nas respostas, não muito alta, mas ainda assim relevante. A tendência à concordância é mais expressiva no que se refere a "Eu percebo que se houver oportunidade, a organização aproveitaria ainda mais minhas habilidades e competências" $(M=3,403 ; D P=$ $1,172)$, "Eu percebo que minha organização está disposta a me ajudar se eu tiver uma necessidade especial" (M $=3,247 ; D P=1,174)$ e "Eu percebo que minha organização realmente se importa com meu bem-estar" $(M=3,211$; $D P=1,173)$. A variável com menor avaliação foi a que "Eu percebo que minha organização se preocupa com minhas opiniões" $(M=2,792 ; D P=1,112)$, em que há uma tendência à discordância.

Estes resultados vão ao encontro do estudo de Zagenczyk et al. (2011) que comprovaram que o suporte organizacional é percebido pelos trabalhadores através do tratamento positivo da organização em termos de equidade, condições de trabalho e de supervisão nas relações, o que garante empenho, esforço e manutenção da associação junto à organização por parte do trabalhador. No entanto, há percepções claramente distintas acerca da importância do construto "apoio organizacional" para os respondentes, dadas as variações de percepções entre as 
variáveis. A organização precisa, portanto, identificar junto aos discordantes o que falta para construir uma política organizacional mais positiva junto aos trabalhadores.

No tocante ao construto "flexibilidade de horário", este se refere à flexibilidade de escolha do horário pelo trabalhador para o cumprimento da jornada de trabalho. De acordo com Galletta, Portoghese e Battistelli (2011), a flexibilidade de horário é um aspecto proporcionado pela autonomia no trabalho que gera nos funcionários um sentimento de responsabilidade pelo sucesso ou insucesso de suas ações. Os resultados indicam que, dentre os respondentes, a "flexibilidade de horário" das organizações a que estão vinculados não os satisfaz $(M=2,527 ; D P$ $=0,908)$, principalmente devido às variáveis "Posso escolher livremente meu horário de entrada e saída" $(M=$ $1,953 ; D P=1,170)$ e "A empresa em que trabalho permite que eu escolha um horário de entrada e saída predefinido (por exemplo, de 8:00hs às 17:00hs, de 9:00 às 18:00hs, de 10:00hs às 19:00hs)" $(M=2,364 ; D P=$ $1,395)$, onde há clara discordância no primeiro caso e tendência à discordância no segundo. Há que destacar o elevado desvio padrão nessas variáveis, mostrando variabilidade de percepções.

Em relação ao construto "política de apoio a dependentes", verifica-se que esse ponto não foi bem avaliado pelos respondentes, mostrando tendência à não concordância $(M=2,376 ; D P=1,090)$. As variáveis "Na empresa em que trabalho estou satisfeito com as políticas de apoio disponibilizadas a dependentes (filhos, enteados, idosos, etc.) como, por exemplo, auxílio creche, licença remunerada, casa de repouso para idosos, plano de saúde, etc." $(M=2,627 ; D P=1,344)$, "As politicas de apoio a dependentes (filho, enteado, idosos etc.) são determinantes para que eu NÃO tenha intenção de sair da organização" $(M=2,329 ; D P=1,282)$ e "Utilizo com frequência as políticas de apoio a dependentes (filhos, enteados, idosos etc.) oferecidas na empresa em que trabalho" $(M=$ 2,$173 ; D P=1,214$ ) indicam médias abaixo da neutralidade, tendendo à discordância, o que coloca em xeque a as políticas de apoio a dependentes concedidas pela organização. Como já referenciado por Wayne et al. (2013), quando os funcionários percebem a contribuição da organização com a prestação de cuidados e apoio aos seus dependentes, ocorre uma retribuição através de atitudes e comportamentos positivos e à redução do turnover.

O construto "Consequências negativas na carreira" $(M=2,282 ; D P=0,824)$ revelou que os respondentes tendem a discordar de todas as afirmações, ou seja, estabelecendo que a organização é injusta quanto ao estabelecimento de consequências negativas na carreira dos empregados que dão atenção às suas vidas familiar $\mathrm{e}$ pessoal durante a jornada de trabalho. Segundo Wayne et al. (2013), as políticas organizacionais que proporcionam apoio à família do empregado estão relacionadas com a redução do conflito entre trabalho e família, das intenções de sair da organização e do burnout, além da elevação dos níveis de satisfação no trabalho e comprometimento afetivo com a organização.

Por fim, os resultados para o construto "intenção de saída" $(M=2,268 ; D P=0,977)$ evidenciou que $75,34 \%$ dos trabalhadores investigados discordam das variáveis que compõem este construto, o que pode ser explicado pela atual recessão econômica do país, pautada em aumento de demissões e redução da oferta de trabalho.

Destaque-se que as respostas das variáveis “A jornada de trabalho na minha empresa é fixa e eu não tenho flexibilidade de escolha" e "Eu penso que estarei trabalhando nesta empresa nos próximos 5 anos" foram invertidas para não comprometer a média dos construtos "flexibilidade de horário" e "intenção de saída", apresentando médias baixas na maior parte das variáveis que os compõem.

\subsection{Regressão Linear Múltipla}

A fim de identificar os fatores que afetam a intenção de saída, foi realizada uma regressão linear múltipla entre a variável dependente "intenção de saída" e as variáveis independentes "apoio organizacional", "flexibilidade de horário", "política de apoio a dependentes", "suporte gerencial" e "consequências negativas na carreira". Os resultados são apresentados nas Tabelas 3 e 4.

Tabela 3. Estatísiticas Gerais do Modelo.

\begin{tabular}{|c|c|c|c|c|c|c|c|c|c|c|}
\hline \multirow[b]{2}{*}{ Modelo } & \multirow[b]{2}{*}{$\mathrm{R}$} & \multirow[b]{2}{*}{$\mathrm{R}^{2}$} & \multirow[b]{2}{*}{$\begin{array}{c}\mathrm{R}^{2} \\
\text { ajustado }\end{array}$} & \multirow[b]{2}{*}{$\begin{array}{c}\text { Erro padrão da } \\
\text { estimativa }\end{array}$} & \multicolumn{5}{|c|}{ Alterações Estatísticas } & \multirow[b]{2}{*}{ Durbin-Watson } \\
\hline & & & & & $\begin{array}{c}\text { Variação } \\
\text { do } \mathrm{R}^{2}\end{array}$ & $\mathrm{~F}$ & df1 & df2 & $\begin{array}{c}\text { Alterações } \\
\text { Sig. F }\end{array}$ & \\
\hline 1 &, $454^{\mathrm{a}}$ & ,206 & ,195 & 87672 & ,206 & 18,624 & 5 & 359 &, 000 & 1,890 \\
\hline
\end{tabular}

Fonte: Elaborado pelos autores com dados da pesquisa ${ }^{1}$.

1 Obs.: Preditores: (Constantes), CNC - consequências negativas na carreira, PAD - política de apoio a dependentes, AO - apoio organizacional. 
Conforme Tabela 3, o modelo sugerido apresenta $R^{2}$ ajustado de 0,195 , ou seja, $19,5 \%$ da variação da intenção de saída é explicada pelos construtos "consequências negativas na carreira", "política de apoio a dependentes" $\mathrm{e}$ "apoio organizacional". Como o modelo explica somente 19,5\% da intenção de saída, pode-se inferir que $80,5 \%$ da variação deste comportamento é explicada por outros construtos que não fizeram parte deste estudo, o que mostra a complexidade do construto "intenção de saída".

$\mathrm{Na}$ Tabela 4 são mostrados os resultados da regressão, levando-se em consideração as variáveis estatisticamente significativas a 5\%. Importante destacar que os construtos "apoio organizacional" e "política de apoio a dependentes" possuem sentido inverso à variável dependente "intenção de saída", ou seja, na percepção dos trabalhadores, essas variáveis estão associadas negativamente à intenção de saída da organização, o que é coerente. Já o construto "consequências negativas na carreira" é positivamente relacionado à "intenção de saída", o que também atende às expectativas. Os construtos "flexibilidade de horário" e "suporte gerencial" não foram percebidos pelos trabalhadores como significativos para explicar a variável dependente "intenção de saída".

Tabela 4. Coeficientes que Apresentaram Significância para Variável Dependente.

\begin{tabular}{|c|c|c|c|c|c|c|c|c|c|c|c|c|}
\hline \multirow{2}{*}{ Variáveis } & \multicolumn{2}{|c|}{$\begin{array}{l}\text { Coeficientes não } \\
\text { padronizados }\end{array}$} & \multirow{2}{*}{$\begin{array}{l}\text { Coef. } \\
\text { padron. } \\
\text { Beta }\end{array}$} & \multirow{2}{*}{$T$} & \multirow{2}{*}{ Sig. } & \multicolumn{2}{|c|}{$\begin{array}{c}\text { 95,0\% Interv. } \\
\text { de Conf. para B }\end{array}$} & \multicolumn{3}{|c|}{ Correlação } & \multicolumn{2}{|c|}{$\begin{array}{l}\text { Estatísticas de } \\
\text { colinearidade }\end{array}$} \\
\hline & Beta & $\begin{array}{c}\text { Erro } \\
\text { Padrão }\end{array}$ & & & & $\begin{array}{l}\text { Limite } \\
\text { Inf. }\end{array}$ & $\begin{array}{l}\text { Limite } \\
\text { Sup. }\end{array}$ & $\begin{array}{c}\text { Ordem } \\
\text { Zero }\end{array}$ & Parcial & Part. & Toler. & VIF \\
\hline (Const.) & 2,336 & ,216 & & 0,796 &, 000 & 1,911 & 2,762 & & & & & \\
\hline $\mathrm{AO}$ &,- 225 &, 065 &,- 210 & $-3,449$ & ,001 &,- 354 &,- 097 &,- 250 &,- 179 &, 10 &, 597 & 1,674 \\
\hline PAD &,- 098 & ,049 &,- 109 & $-2,008$ &, 045 &,- 194 &,- 002 &,- 149 &,- 105 &,- 094 & ,746 & 1,341 \\
\hline $\mathrm{CNC}$ & ,445 & ,057 &, 375 & 7,820 & ,000 & ,333 & ,557 & ,338 & ,382 & ,368 & ,962 & 1,040 \\
\hline
\end{tabular}

Fonte: Elaborado pelos autores com dados da pesquisa ${ }^{2}$.

$\mathrm{Na}$ percepção dos respondentes, os construtos significativos permitem inferir que as organizações investigadas promovem ações que provocam nos empregados o sentimento de bem-estar, valorização, reconhecimento, apoio, atenção e cuidado, de forma que estes percebem o empenho da organização e, assim, a intenção de saída do trabalho é reduzida. A percepção do suporte organizacional pelos trabalhadores tem relação com o tratamento oferecido pela organização, sendo considerado apropriado, digno e harmonioso, envolvendo práticas de RH formais (benefícios sociais) e informais (relação gestor-empregado) (NORONHA, 2015; NASHUKI; OTHMAN; GHAZALI, 2014). O resultado desta investigação evidencia a influência do suporte organizacional na manutenção do vínculo empregado-empregador através de cuidados, consideração e reconhecimento percebido pelos colaboradores (SIQUEIRA; GOMIDE JR., 2004).

O resultado obtido na regressão pelo construto "política de apoio a dependentes" também se apresentou significativo e com associação inversa à intenção de saída da organização, demonstrando que se as organizações investigadas implantarem políticas de apoio a dependentes que sejam utilizadas com frequência regular, elas podem reduzir a intenção de saída do trabalho, aumentar a satisfação e o compromisso no trabalho. As políticas de apoio a dependentes geralmente têm como objetivo reduzir o conflito entre vida pessoal e vida profissional experimentado pelos empregados, além de serem utilizadas como estratégia de recrutamento, ao tornar a empresa mais atrativa a trabalhadores com destaque no mercado (BEAUREGARD; HENRY, 2009). Além disso, as políticas de apoio a dependentes disponibilizadas aos colaboradores influenciam na redução da intenção de saída da organização, e ocorre quando o colaborador se sente satisfeito com as políticas de apoio disponibilizadas a

Variável Dependente: IS - intenção de saída.

Método de estimação: Stepwise.

Testes de validez:

ANOVA: Significativo; Teste de Aleatoriedade: Suporta a hipótese de aleatoriedade; Teste de Aderência Kolmogorov-Smirnov: Suporta hipótese de aderência a distribuição normal; Teste de Homocedasticidade: Suporta a hipótese de homocedasticidade.

2 Obs.: Variável Dependente: IS - intenção de saída.

Preditores: (Constante), AO - apoio organizacional, PAD - política de apoio a dependentes, CNC - consequências negativas na carreira. 
dependentes e na frequência regular de utilização das mesmas (DE OLIVEIRA; CAVAZOTTE; PACIELLO, 2013; ANDERSON; COFFEY; BYERLY, 2002).

A flexibilidade no ambiente de trabalho, disponibilizada através do apoio da organização para a integração das fronteiras trabalho e família, influencia o comprometimento afetivo entre indivíduo e organização, gerando no indivíduo predisposição para "doar energia e lealdade" à organização (FERGUSON; CARLSON; KACMAR, 2015) e isso fica evidenciado nos resultados por meio dos construtos apoio organizacional e políticas de apoio a dependentes.

O resultado na regressão do construto "consequências negativas na carreira" apresentou-se estatisticamente significante e positivamente relacionado à intenção de saída da organização, e permite apontar que, se nas organizações pesquisadas aumenta a intenção de saída do trabalho, é possível que seja relacionado a tal dimensão. Assim, pode-se esperar que, se as organizações promoverem ações que gerem nos colaboradores a percepção de prejuízos ao desenvolvimento de suas carreiras, que estariam associadas a uma cultura organizacional inflexível com profissionais que procuram uma rotina mais equilibrada entre os domínios trabalho e lar, sua intenção de saída aumenta. O referido construto tem relação com o tratamento disponibilizado pela organização quanto a progressões na carreira dos profissionais que dão atenção às suas vidas familiar e pessoal durante a jornada de trabalho (DE OLIVEIRA; CAVAZOTTE; PACIELLO, 2013; ANDERSON; COFFEY; BYERLY, 2002).

Em suma, as hipóteses 2, 4 e 5 são suportadas, enquanto falha-se em confirmar as hipóteses 1 e 3 . No entanto, há que destacar o baixo poder explanatório das variáveis significativas frente à variável dependente de "intenção de saída", dado que o $R^{2}$ ajustado foi de $19,5 \%$, o que implica dizer que há diversas outras dimensões que afetam a satisfação dos empregados e que motivam a intenção de saída, sejam tais dimensões de natureza interna ou externa, pessoais ou conjunturais

\subsection{Teste de Comparações de Médias}

Continuando a análise, foram comparadas as médias das amostras constituídas a partir das características demográficas gênero (masculino e feminino) e local de trabalho (administração pública e iniciativa privada), de forma a identificar a possível existência de percepções distintas entre os grupos com relação às dimensões do suporte organizacional percebido e a intenção de saída do trabalho. O resultado consta da Tabela 5.

Tabela 5. Teste-T de Comparação de Médias - Gênero.

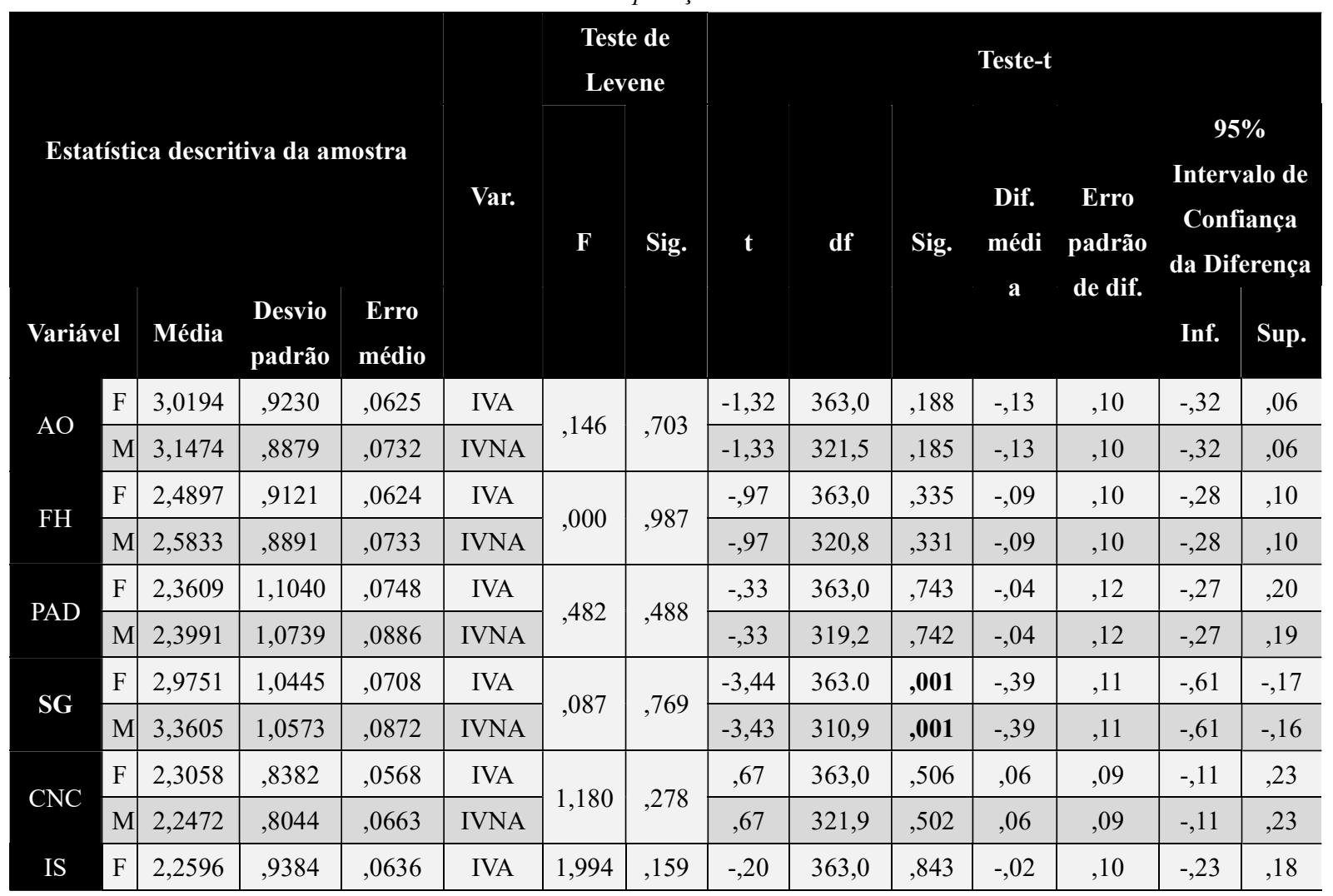




\begin{tabular}{|l|l|l|l|l|l|l|l|l|l|l|l|l|l|}
\hline M & 2,2803 & 1,0349 &, 0854 & IVNA & & &,- 19 & 292,3 &, 846 &,- 02 &, 11 &,- 23 &, 19 \\
\hline
\end{tabular}

Fonte: Elaborado pelos autores com dados da pesquisa ${ }^{3}$.

Constatou-se que não há evidências significativas de que a variação entre gêneros seja um elemento que interfira no posicionamento do trabalhador quanto a intenção de saída do trabalho (variável dependente IS). Os dados evidenciam diferenças significativas apenas para um dos construtos analisados, "suporte gerencial". Alinhado a este resultado, o estudo de Ling Suan e Mohd Nasurdin (2016) evidenciou que trabalhadores do gênero masculino são mais envolvidos no trabalho quando eles têm uma forte percepção do "suporte gerencial", o que pode ser explicado pelo fato dos homens darem maior importância a sua colocação e importância na organização, além de serem competitivos e orientados para a conquista.

Assim, sugere-se que os trabalhadores do gênero masculino sejam estimulados a avaliar o "suporte gerencial" de forma diferenciada, tendendo a auferir mais importância ao "suporte gerencial" das organizações a que estão vinculados para uma maior progressão na carreira, motivação e empenho no trabalho quando comparados a percepção de trabalhadoras do gênero feminino. Em suma, a hipótese 6 não é suportada.

Os resultados apresentados na Tabela 6 demonstram evidências de diferenças significativas para os construtos de "flexibilidade de horário", "suporte gerencial" e "consequências negativas na carreira", o que leva ao entendimento de que há variações de percepção entre trabalhadores de organizações de natureza distinta - pública ou privada. Os resultados sugerem que os servidores da administração pública dão mais importância para estes construtos quando comparados aos trabalhadores de organizações privadas.

Tabela 6. Teste-T de Comparação de Médias - Local de Trabalho.

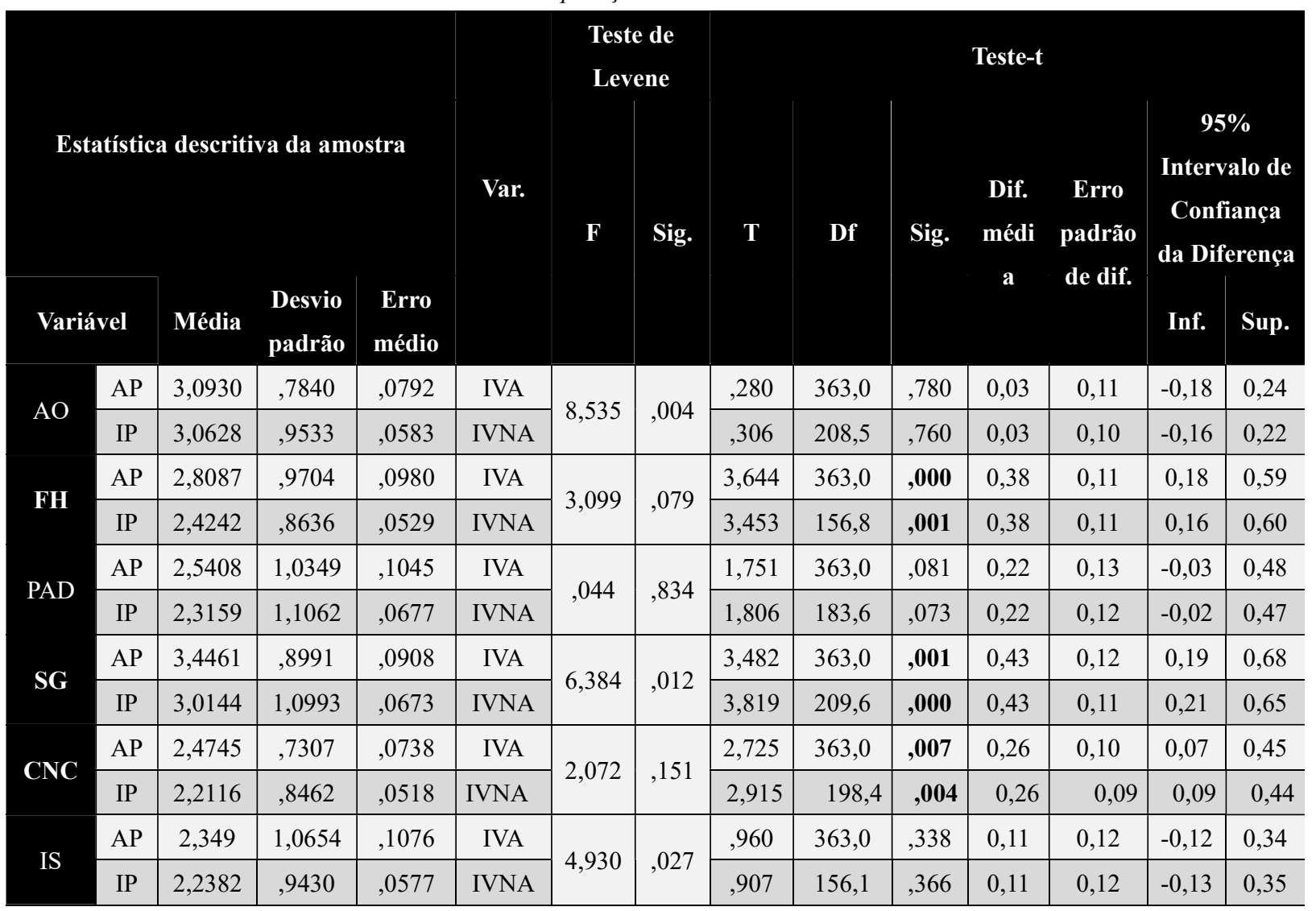

Fonte: Elaborado pelos autores com dados da pesquisa ${ }^{4}$.

\footnotetext{
3 Obs: IVA - igualdade de variância assumida; IVNA - igualdade de variância não assumida; AO - apoio organizacional; FH - flexibilidade de horário; PAD - política de apoio a dependentes; SG - suporte gerencial; CNC - consequências negativas na carreira; IS - intenção de saída; F feminino; e $\mathrm{M}$ - masculino.

4 Obs: IVA - Igualdade de variância assumida; IVNA - Igualdade de variância não assumida; AO - Apoio Organizacional; FH - Flexibilidade
} 
A autonomia no trabalho possibilita a liberdade, discrição e independência para escolha do horário de trabalho, tomada de decisões e escolha de procedimentos e métodos para execução das atividades (GALLETTA; PORTOGHESE; BATTISTELLI, 2011). O resultado apresentado para o construto flexibilidade de horário pode ser explicado devido à maior flexibilidade de horário da jornada de trabalho dos servidores públicos em suas rotinas.

O "suporte gerencial" é descrito como a medida em que os empregados percebem o apoio, incentivo e preocupação dos supervisores (LING SUAN; MOHD NASURDIN, 2016). Com base nos resultados, os trabalhadores da administração pública tendem a conceder maior importância ao suporte gerencial do que os trabalhadores da iniciativa privada, supostamente pela forma da comunicação de supervisão alinhada a um estilo de gestão participativa, ambiente menos competitivo e mais apoio no local de trabalho, tipo de atividade realizada, interação com a equipe, regras de trabalho praticadas na organização, a estabilidade no trabalho e a quantidade de trabalho verificadas no setor público.

Por fim, quanto às "consequências negativas na carreira", o resultado apresentado, provavelmente, deve-se ao fato de os servidores públicos vivenciarem menos conflitos entre trabalho e lar. Segundo Wayne et al. (2013), as políticas organizacionais que proporcionam apoio à família do empregado estão associadas com a redução do conflito trabalho-família, das intenções de sair da organização e do burnout, assim como com a elevação dos níveis de satisfação no trabalho e comprometimento afetivo com a organização. Quanto à variável dependente, "intenção de sair", não houve diferenças significativas entre trabalhadores da administração pública e da iniciativa privada. Em suma, a hipótese 7 é suportada.

\section{Conclusões}

Objetivo deste estudo foi identificar as dimensões do suporte organizacional percebido que afetam a intenção de saída do trabalho. A análise dos dados demonstrou que as dimensões "apoio organizacional", "política de apoio a dependentes" e "consequências negativas na carreira" foram os fatores significativamente percebidos pelos trabalhadores investigados.

As dimensões "apoio organizacional" e "política de apoio a dependentes" influenciam de maneira inversamente proporcional a variável dependente "intenção de saída". Dessa forma, sugere-se que as organizações promovam ações que gerem nos colaboradores o sentimento de bem-estar, valorização, reconhecimento, apoio, atenção e cuidado e implantem políticas de apoio a dependentes que sejam utilizadas com frequência regular. Já a dimensão "consequências negativas na carreira" afeta positivamente a intenção de saída do trabalhador. Assim, sugere-se que as organizações procurem evitar uma cultura organizacional inflexível, já que os profissionais procuram uma rotina mais equilibrada entre os domínios trabalho e lar.

Concluiu-se, a partir dos dados da pesquisa, que boa parte dos respondentes, todos da região Nordeste, tendem a concordar e considerar importante as afirmações das variáveis investigadas nos construtos "apoio organizacional" e "suporte gerencial", o que pode indicar, que estes domínios parecem ser os mais bem geridos pelas empresas onde atuam, e que estas variáveis podem ser relevantes para a continuidade de sua relação com a organização.

Características demográficas de gênero e de natureza pública ou privada da organização revelaram heterogeneidade de percepções nos trabalhadores investigados, uma vez que os resultados indicaram que esses aspectos individuais podem interferir nas dimensões que compõem o suporte organizacional percebido. No entanto, não se constataram evidências significativas para esses aspectos quanto ao posicionamento do trabalhador com relação à intenção de saída do trabalho.

Com base nessas informações, este estudo traz contribuições às organizações na disponibilização de percepções que possam direcionar de forma mais objetiva as estratégias e a alocação de recursos para ações formais e informais de gestão de pessoas que reduzam a intenção de saída dos trabalhadores e favoreçam a manutenção do

de Horário; PAD - Política de Apoio a Dependentes; SG - Suporte Gerencial; CNC - Consequências Negativas na Carreira; IS - Intenção de Saída; AP - Administração Pública; IP - Iniciativa Privada. 
vínculo entre empregado e empregador, com o aumento da satisfação no trabalho e desempenho dos trabalhadores na organização, além de tornar a empresa mais atrativa a trabalhadores com destaque no mercado.

As evidências podem contribuir para que as organizações obtenham vantagens competitivas e reconhecimento no mercado frente ao cenário de intensa competitividade e complexidade na maior parte dos setores econômicos, de forma a minimizar a falta de engajamento do empregado em relação à organização e mesmo desta em relação àquele, com consequente redução do turnover e impacto positivo no desempenho.

Como contribuição teórica, há que destacar a relevância da discussão do suporte organizacional percebido pelo empregado e sua influência na intenção de saída do trabalho em um ambiente destrói empregos em função de novas tecnologias e modelos de negócios. Mais especificamente contribui para a elaboração de políticas organizacionais que interferem na intenção de saída do trabalho, destacando que são poucos os estudos sobre esta temática no contexto brasileiro.

Entretanto, esse estudo possui limitações. Primeiramente, há que destacar a natureza não probabilística da composição da amostra, em que foram investigados profissionais de organizações situadas em 2 estados da região Nordeste, embora fosse exatamente essa a intenção. Logo, os resultados não podem ser generalizados e podem não representar a realidade de outras regiões do país, tendo em vista as diferenças sociais, culturais e econômicas existentes. Além disso, existem outras variáveis não abordadas nesta pesquisa que podem ampliar a capacidade de explicação das práticas organizacionais que estão associadas à intenção de saída do trabalho, tendo em vista que o modelo utilizado explicou somente $19,5 \%$ desta relação.

Para trabalhos complementares, recomenda-se incorporar ao modelo outras variáveis capazes de ampliar o poder de explicação do construto intenção de saída do trabalho. Para aprofundamento das investigações acerca dessa temática, sugere-se, ainda, estudos qualitativos, como forma de ampliar o entendimento da complexidade que este tema envolve.

\section{Referências}

ABUKHALIFEH, A. N.; SOM, A. P. M. The antecedents affecting employee engagement and organizational performance. Asian Social Science, v. 9, n. 7, p. 41, 2013.

ANDERSON, S. E.; COFFEY, B. S.; BYERLY, R. T. Formal organizational initiatives and informal workplace practices: Links to work-family conflict and job-related outcomes. Journal of management, v. 28, n. 6, p. 787-810, 2002.

BEAUREGARD, T. A.; HENRY, L. C. Making the link between work-life balance practices and organizational performance. Human resource management review, v. 19, n. 1, p. 9-22, 2009.

CHANG, W. A.; WANG, Y.; HUANG, T. Work Designed-Related Antecedents of Turnover Intention: A Multilevel Approach. Human Resource Management, v. 52, n. 1, p. 1-26, 2013.

CHEW, J.; CHAN, C. C. A. Human resource practices, organizational commitment and intention to stay. International journal of manpower, v. 29, n. 6, p. 503-522, 2008.

CHO, S.; JOHANSON, M. M.; GUCHAIT, P. Employees intent to leave: A comparison of determinants of intent to leave versus intent to stay. International Journal of Hospitality Management, v. 28, n. 3, p. 374-381, 2009.

DE OLIVEIRA, L. B.; CAVAZOTTE, F. S. C. N.; PACIELLO, R. R. Antecedentes e Consequências dos Conflitos entre Trabalho e Família.: Antecedents and Consequences of Work-Family Conflicts. RAC - Revista de Administração Contemporânea, v. 17, 4, 418-437, July 2013.

ESTIVALETE, V. F. B.; ANDRADE, T. A influência dos valores organizacionais na percepção de suporte organizacional a partir da concepção dos colaboradores do setor bancário. Revista de Administração Mackenzie, v. 13, n. 3, p. 214-244, 2012.

FERGUSON, M.; CARLSON, D.; KACMAR, K. M. Flexing Work Boundaries: The Spillover and Crossover of Workplace Support. Personnel Psychology, v. 68, n. 3, p. 581-614, 2015.

FRANK, F. D.; FINNEGAN, R. P.; TAYLOR, C. R. The race for talent: retaining and engaging workers in the 21 st 
century. Human resource planning, v. 27, n. 3, p. 12-25, 2004.

GAlletTA, M.; PORTOGHESE, I.; BATTISTELLI, A. Intrinsic motivation, job autonomy and turnover intention in the Italian healthcare: The mediating role of affective commitment. Journal of Management Research, v. 3, n. 2, p. 1, 2011.

HAIR Jr., J. H.; BLACK, W.C.; BABIN, B. J.; TATHAM, R. L. Análise multivariada de dados. $6^{\mathrm{a}}$ ed. São Paulo: Bookman, 2009.

IBGE - Instituto Brasileiro de Geografia e Estatística. Pesquisa Nacional por Amostra de Domicílios Contínua PNAD Trimestral. Disponível em: http://www.ibge.gov.br/home/estatistica/indicadores/trabalhoerendimento/pnad_continua. Acesso em: 15 outubro de 2016.

JAMES, J. B.; MCKECHNIE, S.; SWANBERG, J. Predicting employee engagement in an age-diverse retail workforce. Journal of Organizational Behavior, v. 32, n. 2, p. 173-196, 2011.

LING SUAN, C.; MOHD NASURDIN, A. Supervisor support and work engagement of hotel employees in Malaysia: Is it different for men and women? Gender in Management: An International Journal, v. 31, n. 1, p. 2-18, 2016.

LUZ, C. M. D. R.; PAULA, S. L. DE; OLIVEIRA, L. M. B. DE. Organizational commitment, job satisfaction and their possible influences on intent to turnover. Revista de Gestão, v. 25, n. 1, p. 84-101, 2018.

NASHUKI, N. M.; OTHMAN, M.; GHAZALI, H. Predictors of intention to stay for employees of casual dining restaurant in Klang Valley area. International Food Research Journal, v. 21, n. 3, p. 863-871, 2014.

NORONHA, P. A. A associação entre sentido no trabalho, suporte organizacional percebido e variáveis de desempenho. 2015. 62 f. Dissertação (Mestrado em Administração de Empresas) - Fundação Instituto Capixaba de Pesquisas em Contabilidade, Economia e Finanças - FUCAPE, Vitória, 2015.

PURANG, P. Organisational justice and affective commitment: The mediating role of perceived organisational support. Asian Academy of Management Journal, v. 16, n. 1, p. 141-156, 2011.

RHOADES, L.; EISENBERGER, R. Perceived organizational support: a review of the literature. Journal of Applied Psychology, v. 87, n. 4, p. 698-714, 2002.

SHAHNAWAZ, M. G.; JAFRI, M. H. Job Attitudes as Predictor of Employee Turnover among Stayers and Leavers/Hopers. Journal of Management Research, v. 9, n. 3, p. 159-166, 2009.

SIQUEIRA, M. M. M; GOMIDE JR, S. Vínculos do indivíduo com o trabalho e com a organização. Psicologia, Organizações e Trabalho no Brasil, v. 2, p. 300-330, 2004.

WAYNE, J. H.; CASPER, W. J.; MATTHEWS, R. A.; ALLEN, T. D. Family-supportive organization perceptions and organizational commitment: The mediating role of work-family conflict and enrichment and partner attitudes. Journal of Applied Psychology, v. 98, n. 4, p. 606, 2013.

ZAGENCZYK, T. J; GIBNEY, R.; FEW, W. T.; SCOTT, K. L. Psychological contracts and organizational identification: the mediating effect of perceived organizational support. Journal of Labor Research, v. 32 , p. 254-281, 2011. 